\title{
Esophageal injury: Tissue is always the issue
}

\author{
Chuong D. Hoang, MD
}

\footnotetext{
From the Section of Thoracic Surgery, National Institutes of Health, National Cancer Institute, Center for Cancer Research, and The Clinical Center, Bethesda, Md.

Disclosures: Author has nothing to disclose with regard to commercial support.

Received for publication Feb 27, 2018; accepted for publication Feb 28, 2018; available ahead of print Apr 10 , 2018.

Address for reprints: Chuong D. Hoang, MD, Section of Thoracic Surgery, National Cancer Institute-NIH, CCR and The Clinical Center, 10 Center Dr, Mail Code 1201, Room 4-3940, Bethesda, MD 20892 (E-mail: chuong. hoang@nih.gov).

J Thorac Cardiovasc Surg 2018;156:e27

$0022-5223 / \$ 36.00$

Copyright (C 2018 Published by Elsevier Inc. on behalf of The American Association for Thoracic Surgery https://doi.org/10.1016/j.jtcvs.2018.02.083
}

Benign esophageal stricture or damage that requires surgical intervention remains a significant clinical challenge. The esophagus, unlike some other organs, is prone to fibrotic remodeling after tissue loss or injury that often can become intractable, resulting in loss of function with associated morbidity, loss of quality of life, and increased health care costs. ${ }^{1}$ Common therapeutic strategies mandate complex procedures to restore partial esophageal functionality in this context, and modern interventions such as endoluminal stenting are not applicable to all scenarios. $^{2}$ Options for esophageal reconstruction usually involve a new conduit interposition, whereas esophageal-sparing procedures are less widely applied because of multifactorial medical issues. In this issue of the Journal, Pompeo and colleagues ${ }^{3}$ describe their encounter with an unusual and complex problem of esophageal obstruction from compression by a large thoracic aortic aneurysm.

In the case reported by Pompeo and colleagues, ${ }^{3}$ a tortuous, stented (by thoracic endovascular aortic repair) aneurysm caused obstruction of the esophageal tract, leading to an abrupt cutoff of barium contrast on imaging. This finding suggested that the esophageal body might be so compressed as to sustain additional injury. With prudent preoperative planning and clinical insight, Pompeo and colleagues ${ }^{3}$ identified an opportunity to mobilize ("slide") the esophagus intraoperatively, thus allowing a primary repair of the esophageal wall and restoration of luminal patency. Indeed, there was a noncircumferential perforation in the esophageal wall amenable to mucosal closure. This site was protected from further compressive forces by the insertion of an intercostal muscle flap, which also augmented the local vascular supply to this repaired region. This scenario reminds us in such instances to attempt complete preservation of the esophageal body before any considerations of replacement. Presumably, this rare presentation is a plausible precursor to those more frequently

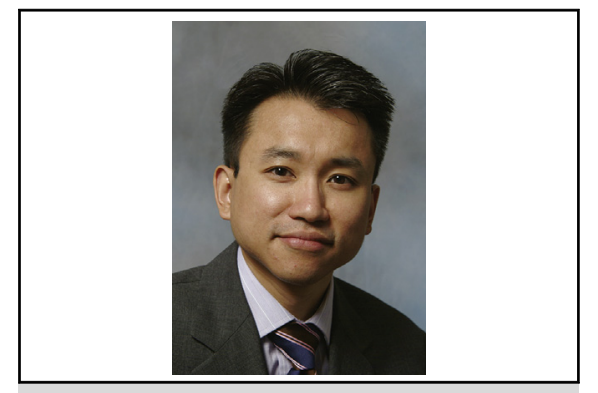

Chuong D. Hoang, MD

Central Message

A novel repair and preservation technique that is based on lateral mobilization of the esophagus is a useful option to consider in complex cases involving esophageal compromise.

See Article page e23.

reported aortoesophageal fistulas occurring after aneurysms fixed by thoracic endovascular aortic repair, with an incidence of $1.7 \%$ to $1.9 \%$. $^{4}$

This useful report adds to the armamentarium of thoracic surgeons faced with decisions to preserve versus replace the esophagus during surgical approaches to esophageal stricture or other injury. In addition, ongoing research efforts in esophageal replacement with tissue-engineering constructs hold promise for revolutionizing this clinical niche. ${ }^{5}$ Degradable bioscaffolds composed of extracellular matrix have been applied as a patch-type plasty to close full-thickness, nonmalignant esophageal wall defects in a small case series $(n=4)$, with good short-term outcomes. ${ }^{6}$

\section{References}

1. Repici A, Small AJ, Mendelson A, Jovani M, Correale L, Hassan C, et al. Natural history and management of refractory benign esophageal strictures. Gastrointest Endosc. 2016;84:222-8.

2. Carrott PW Jr, Low DE. Advances in the management of esophageal perforation. Thorac Surg Clin. 2011;21:541-55.

3. Pompeo E, Elkhouly A, Marchetti AA, Ippoliti A. Sliding esophagoplasty in esophageal obstruction after endovascular stent grafting of thoracic aortic aneurysm. J Thorac Cardiovasc Surg. 2018;156:e23-6.

4. Chiesa R, Melissano G, Marone EM, Marrocco-Trischitta MM, Kahlberg A Aorto-oesophageal and aortobronchial fistulae following thoracic endovascular aortic repair: a national survey. Eur J Vasc Endovasc Surg. 2010;39:273-9.

5. Chian KS, Leong MF, Kono K. Regenerative medicine for oesophageal reconstruction after cancer treatment. Lancet Oncol. 2015;16:e84-92.

6. Nieponice A, Ciotola FF, Nachman F, Jobe BA, Hoppo T, Londono R, et al. Patch esophagoplasty: esophageal reconstruction using biologic scaffolds. Ann Thorac Surg. 2014;97:283-8. 